\title{
Genetic support for random mating between left and right-mouth morphs in the dimorphic scale-eating cichlid fish Perissodus microlepis from Lake Tanganyika
}

\author{
H. J. Lee, S. Pittlik, J. C. Jones, W. Salzburger*, M. Barluenga† \\ AND A. MEYER $\ddagger$ \\ Lehrstuhl für Zoologie und Evolutionsbiologie, Department of Biology, University of \\ Konstanz, Universitätstrasse 10, 78457 Konstanz, Germany
}

\begin{abstract}
Population genetic analyses were conducted to investigate whether random mating occurs between left and right-mouth morphs of the dimorphic scale-eating cichlid fish Perissodus microlepis from two geographical sites in southern Lake Tanganyika. The mitochondrial and nuclear DNA markers (13 microsatellite loci) revealed no genetic differentiation between left and right morphs (i.e. widespread interbreeding). The observed lack of genetic divergence between the different morphs allowed for the exclusion of the possibility of assortative mating between same morph types. The microsalellite data showed no significant departures of heterozygosity from Hardy-Weinberg equilibrium, suggesting purely random mating between the morphs. Overall, this study indicated no genetic evidence for either assortative or disassortative mating, but it did provide support for the random mating hypothesis. Highly significant, albeit weak, spatial population structure was also found when samples of different morphs were pooled according to geographical sites. An additional analysis of two microsatellite loci that were recently suggested to be putatively linked to the genetic locus that determines the laterality of these mouth morphs did not show any such association.
\end{abstract}

Key words: antisymmetry; genetic linkage; heritability; phenotypic plasticity; random mating; scaleeating cichlid fish.

\section{INTRODUCTION}

Natural populations of organisms sometimes exhibit pronounced discontinuous phenotypic variation among individuals. Remarkable examples of such morphological polymorphism include left-right asymmetry morphs in which left or right individuals differ asymmetrically (Palmer, 2004). This asymmetry in form is generally classified into two different types: antisymmetry and directional asymmetry (Palmer, 1996). In the case of antisymmetry, the direction of asymmetry is random: left and right

$\ddagger$ Author to whom correspondence should be addressed. Tel.: $+49(0) 7531884163$; fax: $+49(0) 753188$ 3018; email: axel.meyer@uni-konstanz.de

*Present address: Zoological Institute, University of Basel, Vesalgasse 1, CH-4051 Basel, Switzerland.

†Present address: Museo Nacional de Ciencias Naturales, Jose Gutierrez Abascal 2, 28006 Madrid, Spain. 
morphs are equally common within a species [e.g. direction of mouth opening in the scale-eating cichlid fish Perissodus microlepis Boulenger (Hori, 1993), and the side of the major claw in male fiddler crabs Uca lactea (Yamaguchi, 1977)]. On the other hand, under directional asymmetry, the direction of asymmetry is fixed: most individuals are asymmetrical towards the same direction, left or right [e.g. direction of shell coiling in the snails, Euhadra species (Davison et al., 2005) and Lymnaea peregra (Freeman \& Lundelius, 1982), and eye side in the polymorphic starry flounder Platichthys stellatus (Pallas) (Hashimoto et al., 2002)].

The two types of morphological asymmetry differ in heritability (Palmer, 2004, 2009). In all the 29 cases of antisymmetry known in animals and plants, the direction of asymmetry is not heritable, that is, the trait is not genetically determined (i.e. phenotypically plastic), except for the one case of direction of style bend in enantiostylous flowers of one Heteranthera species (Jesson \& Barrett, 2002). Another exception to this has since been reported for the direction of shell coiling in the southeast Asian camaenid tree snail subgenus Amphidromus sensu stricto (Schilthuizen et al., 2005). By contrast, in every case of directional asymmetry, the direction of asymmetry is heritable, mostly via Mendelian inheritance (Palmer, 2004).

A well-known example of antisymmetry is lateral dimorphism of mouth-opening direction that is found in several Lake Tanganyikan scale-eating cichlid fish species of the genera Perissodus and Plecodus. The heads of these fishes are asymmetrical: one morph has a mouth that is turned to the left [left morph; left-handed in Hori (1993)] and the other morph's mouth opens to the right (right morph; right-handed) (Fig. 1). Note that although Hori's (1993) original definition of left-handed (sinistral) and right-handed (dextral) has recently been re-defined as righty and lefty, respectively (Hori et al., 2007), here the initial definitions are used since in the anatomical literature features are described from the perspective of the subject rather than the observer.

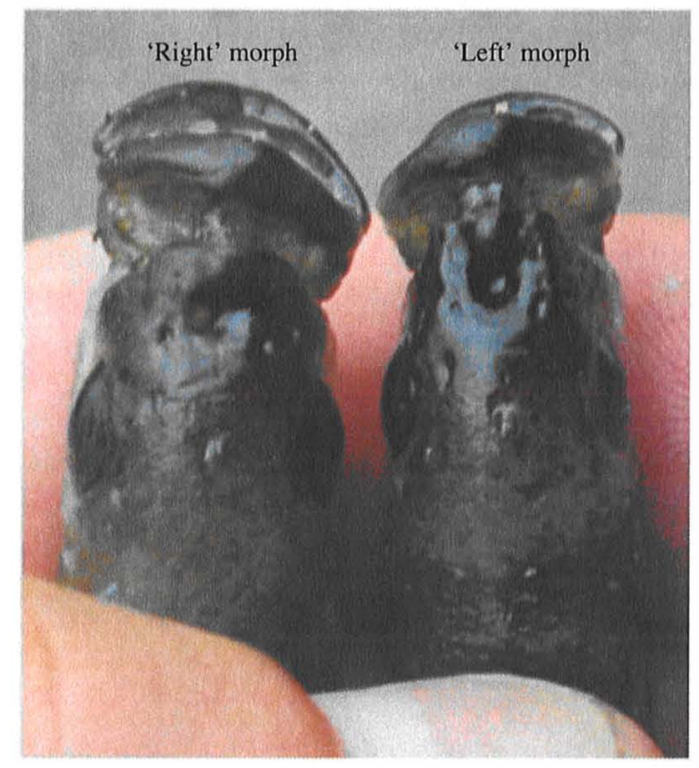

FIG. 1. Heads of the right and left morphs of Lake Tanganyikan scale-eating cichlid fish Perissodus microlepis. 
Perissodus microlepis is one of the nine species of scale-eating cichlids of the tribe Perissodini endemic to Lake Tanganyika (Takahashi et al., 2007). This fish feeds on scales from other fish by ambushing them from behind (Nshombo et al., 1985). Approaching from behind, the asymmetry of their jaws restricts the attack direction of the different morphs to only one side (Hori, 1993). Left morphs attack their prey's right side and right morphs their left side. Interestingly, the number of individuals of each morph fluctuates around an equal 50:50 ratio and is stable over time within a given population (Hori, 1993). This even frequency of both morphs was inferred to be shaped by negative frequency-dependent natural selection, where the rare morph gains a selective advantage over the abundant one (Hori, 1993). Prey are thought to be more alert to being attacked from the preferred side of the more abundant morph. As a consequence, increased prey vigilance would reduce the predation success of the abundant morph, and negative frequency-dependent selection would favour the rarer morph and an equal lateral dimorphism would be maintained.

The direction of mouth opening (i.e. laterality) of P. microlepis is apparently an unusual exception to the commonly observed pattern that a random, external environmental trigger determines the direction of asymmetry in the case of antisymmetry (Palmer, 2004, 2009), the direction of mouth opening (i.e. laterality) of P. microlepis is apparently an unusual exception. The laterality of this fish has been suggested to be genetically determined under a single Mendelian locus with two alleles (where right is dominant over left) (Hori, 1993; Hori et al., 2007). Right-right pairs produce a 2:1 ratio of right:left offspring, left-right pairs a 1:1 offspring and left-left pairs only left offspring (Hori et al., 2007). These estimates were based on field-collected offspring from broods guarded by a pair of parents of known mouth morphs. Parents of this species, however, have the unusual habit of farming-out their fry to other conspecific breeding pairs (i.e. intraspecific brood mixing; Yanagisawa, 1985) and even to other non-conspecific pairs (i.e. interspecific brood mixing; Ochi \& Yanagisawa, 1996). Inconsistent with the Mendelian ratio of right:left $=3: 1$, right-right pairs showed a 2:1 ratio of right:left offspring (right allele is homozygous lethal; Hori et al., 2007). In a recent review, Palmer (2010) has pointed out that the results from the original study (Hori, 1993) are inconsistent with a model where right allele is homozygous lethal and left-left pairs produce only left offspring. The laterality of this fish has recently been suggested to be phenotypically plastic (Van Dooren et al., 2010). The field observation that the laterality of $P$. microlepis is a heritable trait has not yet been confirmed by controlled breeding experiments. Thus, there is no evidence against the laterality of this fish being entirely environmentally determined (i.e. phenotypically plastic). However, Stewart \& Albertson (2010) suggest that the laterality of $P$. microlepis is genetically determined. They found a putative link between two microsatellite markers and the genes for the laterality of the mouth.

There are three main hypotheses on the mating system associated with the observed laterality in P. microlepis: (1) assortative mating, (2) disassortative mating and (3) random mating. The first hypothesis is that in this species mating is assortative according to jaw laterality, so that individuals mate preferentially with some of the same morph. In the case of antisymmetry, Johnson (1982) observed that mating is assortative between individuals of different shell coiling directions in the dimorphic land snails, Partula suturalis on the island of Moorea (French Polynesia). Assortative mating causes genetic divergence between left and right morphs by reducing or even inhibiting gene flow between them [e.g. the land snail Cepaea nemoralis in the 
U.K.; (Johnson, 1976)], which allows the evolution of reproductive isolation, driving sympatric speciation (Fitzpatrick et al., 2008). Surprisingly, no previous studies have been performed to test for assortative mating between antisymmetrical morphs, using genetic data.

The second hypothesis is that individual $P$. microlepis fish matc disassortatively, preferentially with individuals of the different morph. Takahashi \& Hori (2008) observed that reproductive pairings between different morphs occurred more frequently than pairings between the same morphs in the field. They argued that because left-right pairs produce an approximately equal ratio of left:right offspring (Hori et al., 2007), disassortative mating might be an additional mechanism involved in stabilizing the lateral dimorphism in P. microlepis. If the laterality of this fish was determined by non-genetic variation (Van Dooren $e t$ al., 2010), however, then it is difficult to conceive what possible benefits this fish could gain by disassortative mating.

The third hypothesis is that this species mates randomly irrespective of lateral jaw morph. If laterality is not heritable (i.e. phenotypically plastic) and is therefore an example of antisymmetry (Palmer, 2004, 2009), random mating would be most probable because there would be no selective advantages for this fish to breed either assortatively or disassortatively.

In this study, population genetic analyses were carried out to test whether random mating occurs between left and right mouth morphs of $P$. microlepis from two geographical sites in southern Lake Tanganyika. The predictions of three hypotheses were tested by calculating $F_{\mathrm{ST}}$ values and departures of heterozygosity from Hardy-Weinberg equilibrium (HWE) (Table I). The predicted population genetic outcomes from each hypothesis are summarized in Table I. The spatial population genetic structure of this fish was also examined between the sites. In addition, Hori's (1993) two hypotheses were tested: (1) the equal lateral dimorphism hypothesis, where frequencies of left and right morphs are equal and (2) the lateralized foraging behaviour hypothesis, where left morphs only attack the right side of their prey and right morphs the left side.

This study provides the first genetic evidence for widespread interbreeding and most likely, random mating between left and right morphs of $P$. microlepis in a system where the determination of laterality, genetic or environmental, remains unknown.

\section{MATERIALS AND METHODS}

\section{SAMPLE COLLECTION}

Perissodus microlepis samples were obtained with gillnets in September 2004 from two sites in southern Lake Tanganyika, Zambia (Fig. 2). Specimens were sampled randomly with respect to mouth-opening direction. The two sampling sites were (1) Kalambo Village (KV, $08^{\circ} 36^{\prime} 03^{\prime \prime} \mathrm{S} ; 31^{\circ} 11^{\prime} 03^{\prime \prime} \mathrm{E}$ ) and (2) Toby Veall's Lodge (TL, $08^{\circ} 37^{\prime} 21^{\prime \prime} \mathrm{S} ; 31^{\circ} 12^{\prime}$ $\left.01^{\prime \prime} \mathrm{E}\right)$. The geographical surface distance between KV and TL is $c .3 \mathrm{~km}$. This surface distance between the two sampling sites was estimated from the website http://chemicalecology.net/java/lat-long.htm, based on the latitude and longitude of each site.

\section{RATIO OF LEFT AND RIGHT MORPHS IN TWO SITES}

The mouth laterality of each sample was determined independently in the field by eye by two different researchers (A.M. and W.S.) (Fig. 1). A few ambiguous individuals with 
TABLE I. Predicted outcomes from three mating hypotheses between left and right-mouth morphs in Perissodus microlepis where mouth laterality is genetically or environmentally determined. HWE, Hardy-Weinberg equilibrium; $f$, Weir \& Cockerham's (1984) inbreeding coefficient $f$ [ = system of mating of population measured as deviations from HWE genotype frequency expectations (Templeton, 2006)]. The genetic data provide support for the cases highlighted in grey

\begin{tabular}{|c|c|c|c|c|c|}
\hline \multirow[b]{3}{*}{ Hypotheses } & \multicolumn{4}{|c|}{ If laterality is genetically determined } & $\begin{array}{l}\text { If laterality is } \\
\text { environmentally } \\
\text { determined }\end{array}$ \\
\hline & \multicolumn{2}{|c|}{ Linked* } & \multicolumn{2}{|c|}{ Unlinked* } & \multirow{4}{*}{ Random mating } \\
\hline & Predicted $F_{\text {ST }}$ values & Predicted HWE & Predicted $F_{S T}$ values & Predicted HWE & \\
\hline $\begin{array}{l}\text { Assortative } \\
\text { mating }\end{array}$ & Significant $F_{S T}$ & $\begin{array}{l}\text { Deviations from HWE } \\
\text { because of heterozygote } \\
\text { deficiency }(f>0)\end{array}$ & Significant $F_{\mathrm{ST}}$ & HWE $(f=0)$ & \\
\hline $\begin{array}{l}\text { Disassortative } \\
\text { mating }\end{array}$ & Non-significant $F_{\mathrm{ST}}$ & $\begin{array}{l}\text { Deviations from HWE } \\
\text { because of heterozygote } \\
\text { excess }(f<0)\end{array}$ & Non-significant $F_{\mathrm{ST}}$ & HWE $(f=0)$ & \\
\hline Random mating & Non-significant $F_{\mathrm{ST}}$ & HWE $(f=0)$ & Non-significant $F_{\mathrm{ST}}$ & HWE $(f=0)$ & \\
\hline
\end{tabular}

*If microsatellites genotyped in this study are linked or unlinked to loci involved in expression of the sexually selected phenotypic trait, mouth laterality, assuming that the laterality is genetically determined. 


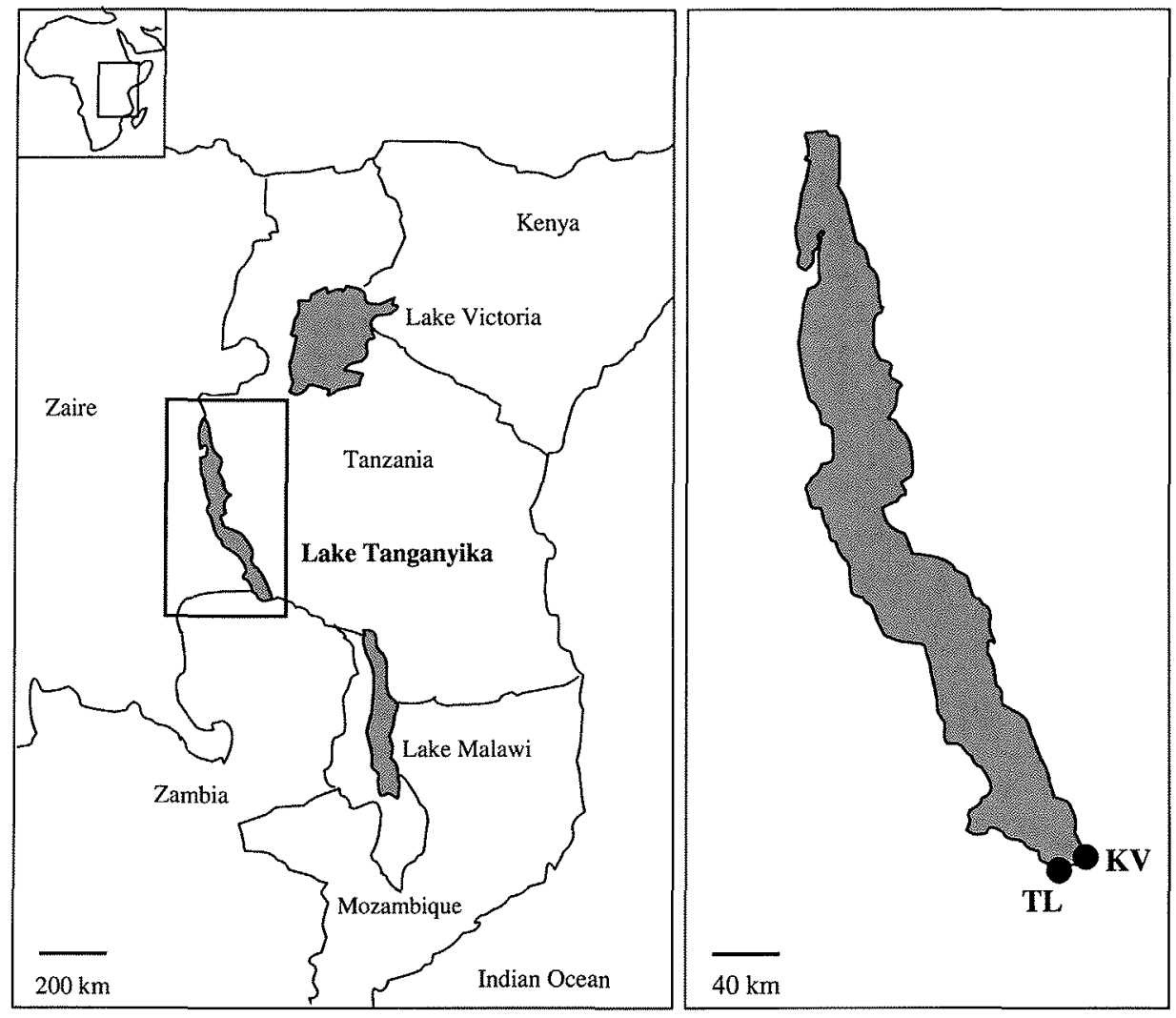

Fig. 2. Sampling sites of Perissodus microlepis in southern Lake Tanganyika, Zambia. KV, Kalambo Village (KV, $08^{\circ} 36^{\prime} 03^{\prime \prime} \mathrm{S} ; 31^{\prime \prime} 11^{\prime} 03^{\prime \prime} \mathrm{E}$ ); TL, Toby Veall's Lodge (TL, $08^{\prime \prime} 37^{\prime} 21^{\prime \prime} \mathrm{S} ; 31^{\circ} 12^{\prime} 01^{\prime \prime} \mathrm{E}$ ).

less pronounced laterality were found among the samples (KV: 1 of 52; TL: 10 of 76). The observed frequencies of left and right morphs, excluding the 11 ambiguous individuals, were KV-left: 23, KV-right: 28; TL-left: 31, TL-right: 35 . Three different $\chi^{2}$ tests were used to determine whether the frequencies of left and right morphs observed differed from a 1:1 ratio (equal lateral dimorphism; Hori, 1993). First, a $\chi^{2}$ test was performed using samples pooled for mouth morph, excluding ambiguous samples. For the next two tests, the 11 ambiguous samples were included; first these fish were assigned to the left morph category, and second to the right-morph category. Only samples with clear differences in laterality were used for genetic analyses.

\section{LATERALIZED FORAGING BEHAVIOUR OF MOUTH MORPHS}

Three left morph individuals and five right morph individuals of $P$. microlepis were collected at TL in Lake Tanganyika and immediately shipped to the animal research facility (TFA) at the University of Konstanz. To determine whether left morph individuals only attack the right side of prey fish, and right morph individuals the left side, eight scale-eaters were kept in individual tanks with one prey fish, a Central American cichlid, Amphilophus citrinellus (Günther). After 7 days, the prey fish were taken out of each tank and were examined for scars on either side of their bodies. The observed lack of scales was caused by attacks from P. microlepis. 


\section{MITOCHONDRIAL DNA SEQUENCING AND DATA ANALYSES}

Genomic DNA was isolated from a small piece of fin tissue, using a proteinase $K$ digestion followed by sodium chloride extraction and ethanol precipitation (Bruford et al., 1998). Mitochondrial DNA (mtDNA) control region was amplified with the published primers, LProF (Meyer et al., 1994) and TDK-DHG (Lee et al., 1995), using standard polymerase chain reaction (PCR) conditions with $50^{\circ} \mathrm{C}$ for annealing temperature $\left(T_{\mathrm{a}}\right)$. Amplified PCR products were purified with QIAquick PCR Purification Kit (Qiagen; www.qiagen.com) following the manufacturer's recommendations. The purified mtDNA fragments were subject to direct sequencing in the forward and reverse directions using the same forward and reverse primers as in the PCR and the BigDye Terminator 3.1 Cycle Sequencing Ready Reaction Kit (Applied Biosystems). All reactions for DNA sequencing were run on a 3130xl DNA Analyser (Applied Biosystems; www.appliedbiosystems.com) and analysed with ABI PRISM DNA Sequencing Analysis Software version 5.3.1. The DNA sequences were edited using Chromas version 2.01 software. Alignment of sequences was conducted using ClustalW2 and then verified by eye. A total of 669 base pairs (bp) of sequence of the mtDNA control region were recovered from 89 samples (KV-left: 20, KV-right: 21, TL-left: 22, and TL-right: 26).

The number of polymorphic sites, mtDNA haplotypes, haplotype diversity $(h)$ and nucleotide diversity $(\pi)$ were calculated for each left and right sample of $P$. microlepis within two sites (KV and TL) using Arlequin 3.11 (Excoffier et al., 2005). The rarefaction method was employed using CONTRIB 1.02 (Petit et al., 1998) to calculate haplotype richness that was corrected for unequal sample sizes among the four sampling groups.

To explore the phylogenetic relationships among the mtDNA haplotypes, a network approach was employed using TCS 1.21 (Clement et al., 2000), which uses the statistical parsimony method described in Templeton et al. (1992). A single deletion mutation was treated as a fifth state as it was retained by five different haplotypes (H13-17). Ambiguous connections in the haplotype network generated by TCS were resolved following the criteria outlined in Templeton \& Sing (1993) and Crandall \& Templeton (1993).

To estimate inter-morph and spatial genetic structure of $P$. microlepis, a hierarchical analysis of molecular variance (AMOVA; Excoffier et al., 1992) was performed using Arlequin. The inter-morph and spatial AMOVA analysis was carried out by grouping samples of left and right morphs according to geographical sites: the KV group comprised KV-left and KVright and the TL group comprised TL-left and TL-right. This AMOVA analysis partitioned the total molecular variance between geographical sites $\left(F_{\mathrm{CT}}=\right.$ spatial genetic variation), between left and right morphs within sites $\left(F_{\mathrm{SC}}=\right.$ inter-morph genetic variation) and within samples irrespective of group $\left(F_{\mathrm{ST}}\right)$.

To further examine inter-morph and spatial genetic differentiation between samples, exact tests for population differentiation (Raymond \& Rousset, 1995) as well as calculation of pair-wise estimates of $F_{\text {ST }}$ (Weir \& Cockerham, 1984) were carried out using GENEPOP 4.0 (Rousset, 2008). Another exact test was then performed by pooling samples of both mouth morphs within geographical sites, which could be justified because the AMOVA had shown no significant inter-morph variation within sites. The $95 \%$ significance levels for pairwise exact tests of genetic differentiation were adjusted, using a Bonferroni correction (i.e. $P=0.05 / 6 \approx 0.0083$ ).

\section{MICROSATELLITES GENOTYPING AND ANALYSES}

Thirteen nuclear microsatellite loci were genotyped for $P$. microlepis samples with the primers that had been developed for the African cichlid fish Astatotilapia burtoni (Günther) (Sanetra et al., 2009).

The number of alleles per locus $\left(N_{\mathrm{a}}\right)$, expected heterozygosity $\left(H_{\mathrm{E}}\right)$, observed heterozygosity $\left(H_{\mathrm{O}}\right)$ and allelic richness (AR) within the four samples were calculated using FSTAT 2.9.3.2 (Goudet, 2001). To test for random mating between left and right morphs of $P$. microlepis, HWE deviations were estimated for each sample at each locus by calculating the inbreeding coefficient $f$ (equivalent to Wright's $F_{\text {IS }}$ ) of Weir \& Cockerham (1984), as implemented in GENEPOP. The $f$ values for each sample across the 13 loci were also calculated. The significance levels of every exact test for HWE were adjusted using the Bonferroni correction. 
Genotypes at the 13 microsatellite loci were tested for linkage disequilibrium (LD) among pairs of loci for the entire pooled samples of $P$. microlepis using GENEPOP.

The inter-morph and spatial AMOVA analysis was conducted for 13 microsatellite loci, using the same groupings as were used for the mtDNA data (see above). The inter-morph and spatial population differentiation analyses were then performed for 13 microsatellite loci.

Following a quantitative trait-locus (QTL) analysis of an interspecific cross of two Lake Malawi cichlids, Stewart \& Albertson (2010) inferred that two microsatellite loci (GM294, UNH2101) are linked to the locus for laterality of the mouth in this species. They used the polymorphic marker (UNH2101) to genotype left and right juveniles from a set of young from one female. This study also tests whether the two microsatellite loci identified by Stewart \& Albertson (2010) do segregate left and right morphs of P. microlepis at the population level. Sample sizes were 51 left and 59 right.

\section{RESULTS}

\section{RATIO OF LEFT AND RIGHT MORPHS IN TWO SITES}

Three different $\chi^{2}$ tests showed no significant deviations from a 1:1 ratio of left:right mouth morphs in $P$. microlepis (Table II), providing support for the hypothesis of equal abundance for both lateral morphs (Hori, 1993).

\section{LATERALIZED FORAGING BEHAVIOUR OF MOUTH MORPHS}

In the laboratory test, almost all individuals exhibited the expected foraging behaviour for their morph. All three individuals of the left morph only attacked the right side of their prey fish, A. citrinellus. In addition, scars and missing scales were only observed on their right side. Similarly, scars were only found on the left side of the prey fish for lour of five right morph individuals. Only one right morph individual attacked both sides of its prey fish in the laboratory test.

\section{MTDNA CONTROL REGION}

A total of $17 \mathrm{mtDNA}$ haplotypes were identified in the total of $89 \mathrm{P}$. microlepis samples that were sequenced (Table III; Fig. 3). Sequences of these haplotypes are

TABLE II. Three different $\chi^{2}$ analyses were performed to test the frequency of lateral dimorphism in Perissodus microlepis at two geographical sites in southern Lake Tanganyika. No test showed a significant deviation from a 1:1 ratio of left:right morphs

\begin{tabular}{lcccc}
\hline Samples & Left:right & $\chi^{2}$ value & d.f. & $P$ \\
\hline $\begin{array}{l}\text { Samples with clear differences in } \\
\quad \text { laterality }\end{array}$ & $54: 63$ & 0.692 & 1 & 0.405 \\
$\begin{array}{l}\text { Samples with clear differences in } \\
\quad \text { laterality + } 11 \text { ambiguous samples } \\
\text { assigned to the left morph category }\end{array}$ & $65: 63$ & 0.031 & 1 & 0.860 \\
$\begin{array}{l}\text { Samples with clear differences in } \\
\text { laterality + } 11 \text { ambiguous samples } \\
\text { assigned to the right morph category }\end{array}$ & $54: 74$ & 3.125 & 1 & 0.077 \\
\hline
\end{tabular}

d.f., degree of freedom. 
TABLE III. Summary of genetic diversity in left and right samples of Perissodus microlepis at mtDNA control region (669 bp)

\begin{tabular}{lcccccc}
\hline & $\begin{array}{c}\text { Sample } \\
\text { sizes } \\
(N)\end{array}$ & $\begin{array}{c}\text { No. of } \\
\text { polymorphic } \\
\text { sites }\end{array}$ & $\begin{array}{c}\text { No. of } \\
\text { haplotypes }\end{array}$ & $\begin{array}{c}\text { Haplotype } \\
\text { richness }\end{array}$ & $\begin{array}{c}\text { Haplotype } \\
\text { diversity }(h)\end{array}$ & $\begin{array}{c}\text { Nucleotide } \\
\text { diversity }(\pi)\end{array}$ \\
\hline KV-left & 20 & 11 & 8 & 7.00 & $0.7842 \pm 0.0840$ & $0.0030 \pm 0.0020$ \\
KV-right & 21 & 12 & 12 & 10.57 & $0.8810 \pm 0.0593$ & $0.0050 \pm 0.0030$ \\
TL-left & 22 & 11 & 6 & 4.73 & $0.7273 \pm 0.0706$ & $0.0054 \pm 0.0032$ \\
TL-right & 26 & 9 & 5 & 3.54 & $0.6831 \pm 0.0681$ & $0.0048 \pm 0.0028$ \\
Total & 89 & 16 & 17 & - & $0.7610 \pm 0.0377$ & $0.0046 \pm 0.0027$ \\
\hline
\end{tabular}

KV, Kalambo Village; TL, Toby Veall's Lodge.

available under GenBank accession numbers GU573821-GU573837. Among the 17 haplotypes, nine were found only in one individual (i.e. singleton) in this sample. Five haplotypes (H13-17) possessed a deletion mutation at the same 641 bp nucleotide position along the $669 \mathrm{bp}$ of mtDNA control region. The overall values of $h$ and $\pi$ for the entire pooled mtDNA data set were $0.7610 \pm 0.0377$ and $0.0046 \pm 0.0027$,

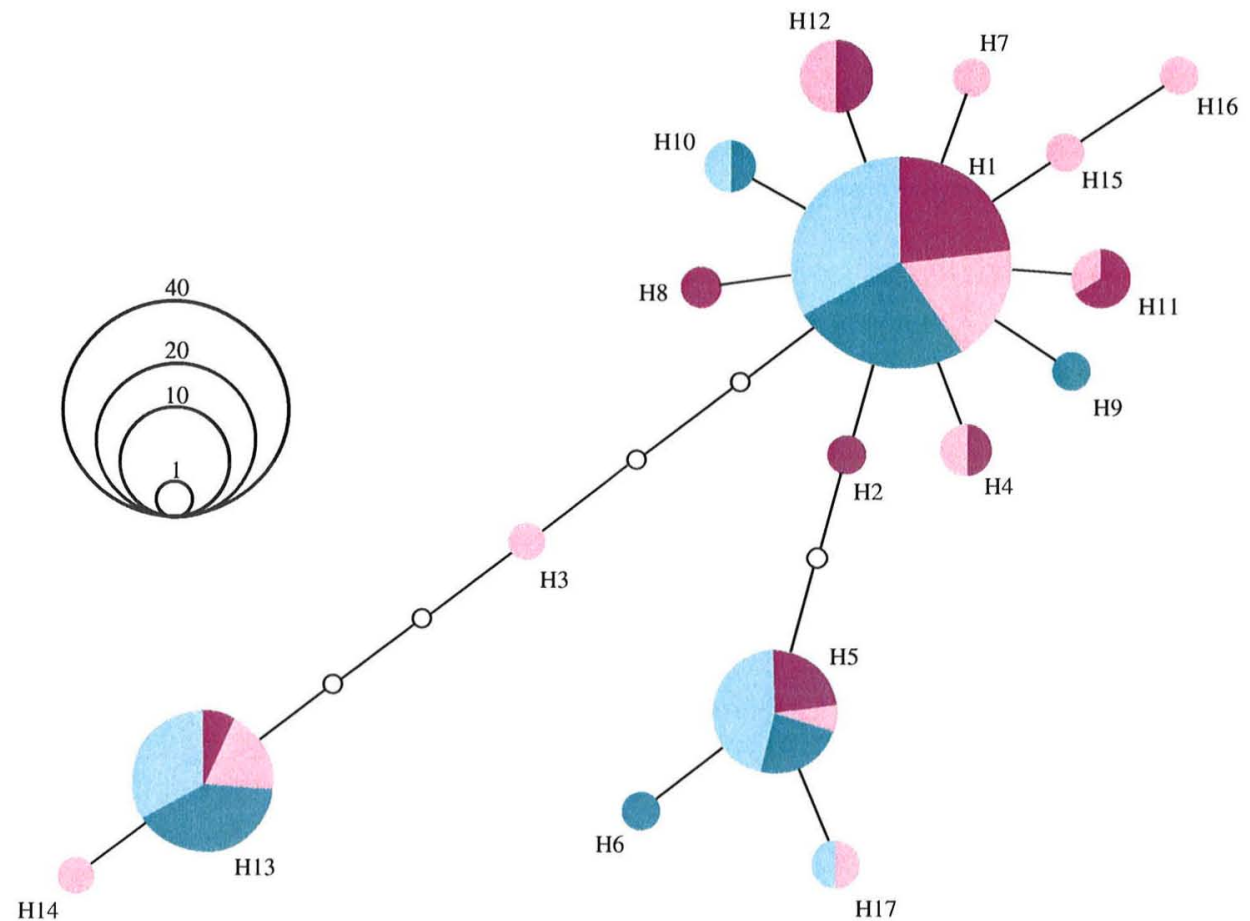

FIG. 3. A haplotype network based on the mtDNA control region for Perissodus microlepis. Each node in the network represents a single mutational step between haplotypes. The area of the circle is proportional to the number of individuals with that haplotype. Small, unfilled circles indicate intermediate haplotypes that are not present in these samples but are inferred mutations for this network. 대, TL-right; 1 , TL-left; , KV-right; 1 , KV-left. KV, Kalambo Village; TL, Toby Veall's Lodge. 
respectively (Table III). In the complete data set, the transition to transversion ratio was 4.3:1.

All the miDNA haplotypes that satisfied the probability of parsimony by $95 \%$ (as defined in Templeton et al., 1992) were connected to a single network (Fig. 3). The haplotype network was centred on the most common haplotype (H1), which consisted of 39 individuals (44\% of total sample) and was detected in all four sampled groups (both localities and jaw morphs) (Fig. 3).

The hierarchical AMOVA of the mtDNA control region data revealed neither significant inter-morph nor spatial genetic structure, although molecular variances partitioned between sites $\left(F_{\mathrm{CT}}=0.0252\right)$ were greater than between mouth morphs within sites $\left(F_{\mathrm{SC}}=-0.024\right)$ (Table IV). The exact tests for population differentiation showed no significant differentiation between any pairs of left and right samples (e.g. left $v$. right comparisons within two sites: KV-left $v$. KV-right: $F_{\mathrm{ST}}=-0.0166$, $P>0.05$; TL-left $v$. TL-right: $F_{\mathrm{ST}}=-0.0262, P>0.05$; Table V). The exact test between the pooled KV and TL spatial samples, however, revealed significant differentiation $\left(F_{\mathrm{ST}}=0.0151, P<0.01\right)$, probably because of increased statistical power owing to the increase in sample size.

\section{MICROSATELLITES}

The 13 microsatellite loci varied widely in number of alleles $\left(N_{\mathrm{a}}: 2-13\right.$, mean $=$ 6.0), expected heterozygosity $\left(H_{\mathrm{E}}: 0 \cdot 16-0 \cdot 89\right.$, mean $\left.=0 \cdot 64\right)$, observed heterozygosity $\left(H_{\mathrm{O}}: 0.17-0.90\right.$, mean $\left.=0.62\right)$ and allelic richness (AR: $1.98-10.79$, mean $=$ 5.24) across the four samples (Appendix). The $f$ values of the four samples across the 13 loci were close to zero (KV-left: -0.0008; KV-right: 0.0493; TL-left: 0.0195; TL-right: 0.0549). As a consequence, all four samples conformed to HWE expectations at all microsatellite loci except for the TL-right sample at Abur117 locus (Appendix), suggesting random mating at the loci tested. Tests of genotypic LD within the entire pooled samples between the 13 loci showed no significant association of alleles except for between Abur90 and Abur162 $(P<0.05)$, suggesting that all loci but these two can be treated as independent markers.

Similar to the results of mtDNA control region, the hierarchical AMOVA for the 13 microsatellite loci showed neither significant inter-morph nor spatial population structure (Table IV). The genetic variation among samples irrespective of group was significant, although small ( $F_{\mathrm{ST}}=0.0094, P<0.01$; Table IV). The exact tests for population differentiation revealed no significant differentiation between left and right samples at either of two sites (KV-left $v$. KV-right: $F_{\mathrm{ST}}=-0.0001, P>0.05$; TL-left $v$. TL-right: $F_{\mathrm{ST}}=0.0079, P>0.05$; Table V). The exact tests between two different samples from different sites, however, were always significant (except for $\mathrm{KV}$-left $v$. TL-right; Table V). As a result, the exact test between the pooled $\mathrm{KV}$ and TL spatial samples revealed highly significant, albeit weak, genetic differentiation $\left(F_{\mathrm{ST}}=0.0088, P<0.001\right)$.

The test of the two microsatellites putatively linked by Stewart \& Albertson (2010) found no allelic variation in GM294 whereas eight different alleles were identified in UNH2101. [cf. Stewart \& Albertson (2010) two alleles: a putative A (right) allele $150 \mathrm{bp}$ in length and a B (left) allele $158 \mathrm{bp}$ in length.] This study has found no evidence for linkage between UNH2101 and the genes for laterality of the mouth at the population level (Fig. 4). 
TABLE IV. Hierarchical AMOVA of inter-morph and spatial genetic structure in Perissodus microlepis using the mtDNA control region as well as 13 microsatellite loci. The analyses were performed by grouping left and right samples of $P$. microlepis according to the sampling sites. Permutations $(16000)$ were carried out separately for each AMOVA

\begin{tabular}{|c|c|c|c|c|c|c|c|}
\hline Locus & Source of variation & d.f. & Sum of squares & $\begin{array}{l}\text { Variance } \\
\text { components }\end{array}$ & $\begin{array}{c}\text { Variation } \\
(\%)\end{array}$ & Fixation indices & $P$ \\
\hline \multirow{4}{*}{$\begin{array}{l}\text { mtDNA control } \\
\text { region }\end{array}$} & Between sites & 1 & 0.634 & $0.00965 \mathrm{Va}$ & $2 \cdot 52$ & $F_{\mathrm{CT}}=0.0252$ & $>0.05$ \\
\hline & Between mouth morphs within sites & 2 & 0.415 & $-0.00786 \mathrm{Vb}$ & -2.05 & $F_{\mathrm{SC}}=-0.0240$ & $>0.05$ \\
\hline & Within samples & 85 & 32.434 & $0.38158 \mathrm{Vc}$ & 99.53 & $F_{\mathrm{ST}}=0.0047$ & $>0.05$ \\
\hline & Total & 88 & 33.483 & 0.38337 & & & \\
\hline \multirow{4}{*}{ Microsatellites } & Between sites & 1 & 6.419 & $0.02199 \mathrm{Va}$ & 0.63 & $F_{\mathrm{CT}}=0.0063$ & $>0.05$ \\
\hline & Between mouth morphs within sites & 2 & $8 \cdot 101$ & $0.01074 \mathrm{Vb}$ & 0.31 & $F_{\mathrm{SC}}=0.0031$ & $>0.05$ \\
\hline & Within samples & 214 & 741.750 & $3.46612 \mathrm{Vc}$ & 99.06 & $F_{\mathrm{ST}}=0.0094$ & $<0.01$ \\
\hline & Total & 217 & $756 \cdot 271$ & 3.49886 & & & \\
\hline
\end{tabular}


TABLE V. Estimates of genetic differentiation $\left(F_{\mathrm{ST}}\right)$ between left and right samples of Perissodus microlepis. Numbers above the diagonal represent $F_{\mathrm{ST}}$ values based on mtDNA control region, and numbers below the diagonal represent $F_{\mathrm{ST}}$ values based on 13 microsatellite loci. The significant levels were adjusted, using the Bonferroni correction for multiple testing (i.e. $P=0.05 / 6 \approx 0.0083$ ). Significant deviations from genetic homogeneity by exact tests are shown in uppercase letters that are given above each $F_{\mathrm{ST}}$ value. KV: Kalambo Village; TL: Toby Veall's Lodge

\begin{tabular}{lccrr}
\hline & KV-left & KV-right & TL-left & TL-right \\
\hline KV-left & & $-0.0166^{\mathrm{NS}}$ & $0.0076^{\mathrm{NS}}$ & $-0.0031^{\mathrm{NS}}$ \\
KV-right & $-0.0001^{\mathrm{NS}}$ & & $-0.0011^{\mathrm{NS}}$ & $0.0153^{\mathrm{NS}}$ \\
TL-left & $0.0172^{* * *}$ & $0.0158^{* *}$ & & $-0.0262^{\mathrm{NS}}$ \\
TL-right & $0.0045^{\mathrm{NS}}$ & $0.0017^{*}$ & $0.0079^{\mathrm{NS}}$ & \\
\hline
\end{tabular}

NS, not significant; $* P<0.05 ; * * P<0.01 ; * * * P<0.001$.

\section{DISCUSSION}

This study provides the first genetic evidence for random mating between left and right mouth morphs of the dimorphic P. microlepis. The observed lack of genetic divergence between the mouth morphs (non-significant $F_{\mathrm{ST}}$ values) suggests that there is a high degree of contemporary gene flow between morphs (i.e. widespread interbreeding). This lack of divergence would seem to rule out the possibility of assortative mating between individuals of the same mouth morphs in P. microlepis (Templeton, 2006; Table I), but so far cannot distinguish between disassortative or random mating as alternative mating systems in this species. No departure of heterozygosity from HWE and $f$ values close to zero at any of the 13 microsatellite loci does, however, provide support for the random mating hypothesis.

Contrary to the result in this study, assortative mating by the direction of asymmetry has been reported in antisymmetrical morphs. Assortative mating occurs according to the direction of shell coiling in the dimorphic [right-handed (dextral) and lefthanded (sinistral)] land snail, Partula suturalis on the island of Moorea (Johnson, 1982). In no-choice laboratory experiments, Johnson (1982) observed that pairs of $P$. suturalis with same shell coiling morphs mated five times more frequently than did pairs with different morphs. Assortative mating offers an opportunity for genetic divergence between dextral and sinistral subpopulations by suppressing gene flow between them [e.g. the land snail C. nemoralis in the U.K.; (Johnson, 1976)]. This limitation of gene flow promotes the evolution of reproductive isolation, driving speciation in the absence of geographical barriers (i.e. sympatric speciation; Fitzpatrick et al., 2008).

This finding of no genetic structure between left and right morphs of $P$. microlepis cannot reject the disassortative mating hypothesis that was proposed by Takahashi \& Hori (2008) in their field-based observational study (Table I). The genetic signature of disassortative mating (i.e. significant deviations from HWE because of heterozygote excess), however, could not be detected. One case of a very small negative $f$ value $(-0.0008)$ was found in the KV-left sample. Large negative $f$ values that depart significantly from HWE suggest disassortative mating (Templeton, 2006). Nevertheless, the data to test the prediction (i.e. heterozygote excess) of the disassortative mating hypothesis directly could not be exploited. The population genetic consequences of 


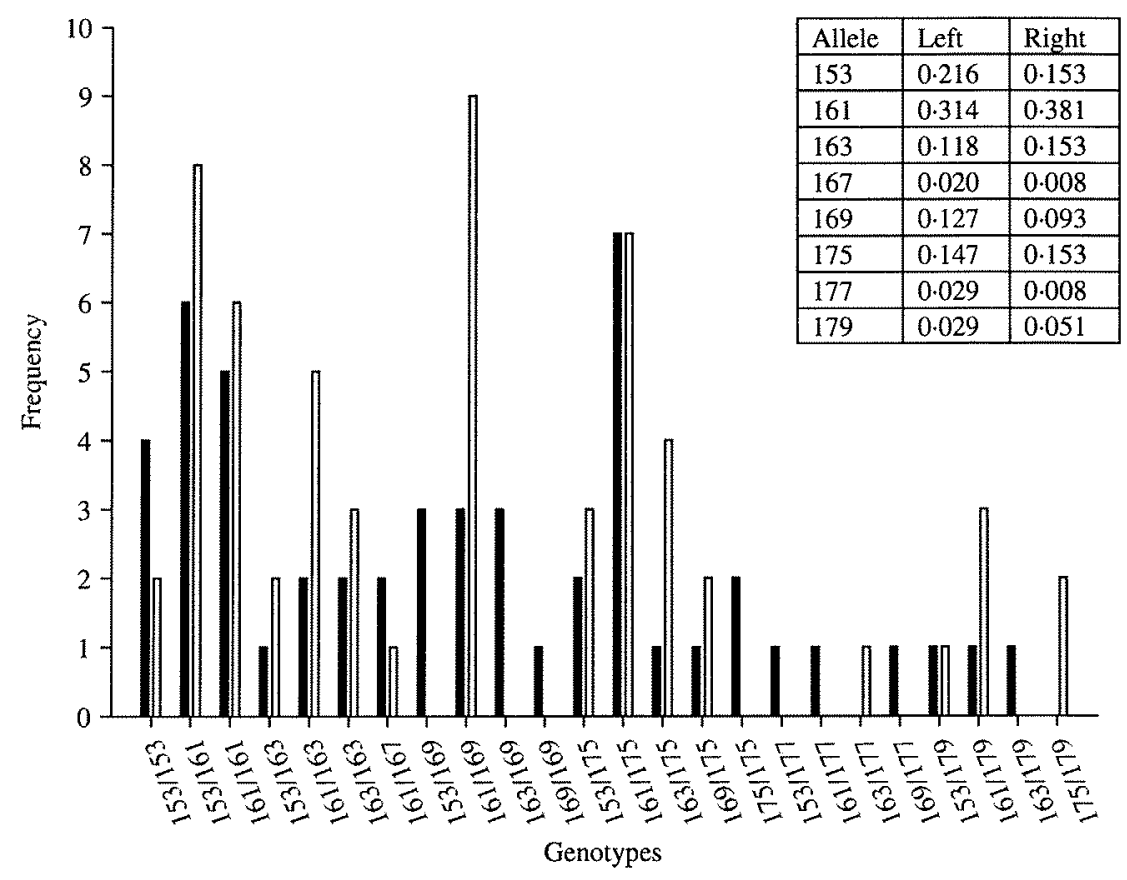

FIG. 4. Genotype frequency distribution between left ( $)$ and right-mouth ( $\square$ ) morphs of Perissodus microlepis at UNH2101. The UNH2101 is putatively linked to the gene for mouth laterality according to Stewart \& Albertson (2010) who observed only two alleles [A (right allele) - $150 \mathrm{bp}$ and B (left allele) - $158 \mathrm{bp}$ ] at this locus. However, eight different alleles were detected in the present study. Alleles, 153 and 161 , were presumed to correspond to alleles, $\mathrm{A}$ and $\mathrm{B}$. No patterns of segregation of particular alleles were found according to mouth morphs. If this locus is linked to the gene for mouth laterality, left individuals would be expected to be homozygous for a putative left allele, while right individuals would be expected to be heterozygous for left and right alleles (Hori et al., 2007; Stewart \& Albertson, 2010), but this is not found. The small table in the figure shows the frequency of each allele for left and right-morphed individuals.

disassortative mating are locus-specific, meaning that this mating regime can only affect loci involved in the expression of the sexually selected phenotypic trait (i.e. mouth laterality in this study) and their linked loci (Templeton, 2006; Table I).

If the laterality of $P$. microlepis is a heritable trait with simple Mendelian genetics as suggested by Hori (1993) and Hori et al. (2007), the disassortative mating hypothesis remains possible, but perhaps not plausible. Among field-caught offspring from broods guarded by a pair of parents of known asymmetry, Hori et al. (2007) observed that a right-right pair yielded a 2:1 ratio of right:left offspring, which is different from the ratio of right:left $=3: 1$ expected under simple Mendelian genetics. They proposed two hypotheses to explain this abnormal ratio: (1) lethality of homozygotes for the dominant right allele or (2) incompatibility between gametes possessing the dominant right allele. Under either hypothesis, if females can tell the mouth laterality of potential mates, then right females should prefer left mates because mating with left males will result in them gaining higher reproductive success than mating with right males (Hori et al., 2007). The selective advantage of 
mating with individuals of the other morph may allow for the evolution of disassortative mating, which in turn stabilizes the lateral dimorphism in $P$. microlepis (Takahashi \& Hori, 2008). Schilthuizen et al. (2007) showed that disassortative mating occurred between dextral and sinistral morphs of the dimorphic south-east Asian camaenid tree snail Amphidromus inversus on Kapas Island, Malaysia. They argued that disassortative mating facilitates the maintenance of phenotypic dimorphism in the snail populations (Schilthuizen et al., 2007).

If the laterality of $P$. microlepis is not a heritable trait (i.e. phenotypically plastic) as suggested by Palmer $(2004,2009)$, random mating would be expected. If the laterality of this fish is determined by phenotypic plasticity, left and right morphs would not encounter any selective pressure facilitating the evolution of either assortative or disassortative mating. The majority of the four sampling groups of $P$. microlepis conformed to HWE expectations at all 13 microsatellite loci examined, which suggests that these loci reflect entirely random mating in this fish, in support of the random mating hypothesis. In their recent controlled laboratory-based foraging experiments, Van Dooren et al. (2010) found that laterality in P. microlepis has a strong phenotypic component, lateralized foraging bchaviour amplifies the extent of morphological asymmetry in adults due to phenotypic plasticity. Although the authors do not know whether genes are also involved in determining laterality, they propose that phenotypic plasticity at least contributes to trait variation in $P$. microlepis. This finding of strong plasticity in mouth-opening direction in P. microlepis would tend to lend support to the random mating hypothesis.

This study indicates small but significant amounts of spatial genetic structuring between two geographically adjacent populations of $P$. microlepis (although not for AMOVA). This observed spatial structure suggests that this species has only limited ability for dispersal. This result is consistent with the recent finding of highly significant genetic structure among six populations of $P$. microlepis in southern Lake Tanganyika at $c .6-43 \mathrm{~km}$ geographic scale, based on variation in a smaller portion of the orthologous mtDNA control region (356 bp) (Koblmüller et al., 2009).

The samples showed a 1:1 ratio of left:right morphs of $P$. microlepis from two geographical sites in southern Lake Tanganyika, as was found before by Hori (1993). The lateralized foraging behaviour hypothesis, where left morphed fish only attack the right sides of their prey and right morphs the left sides, was also supported by the laboratory experiments.

A more complete understanding of the mating system of $P$. microlepis will be aided by additional laboratory-based behavioural experiments to directly test the disassortative-random mating hypotheses. Furthermore, direct estimation of the laterality ratio of broods from different experimental crosses between left and right morphs in the laboratory is required to determine the inheritance pattern of the laterality of $P$. microlepis precisely. A laboratory-based study could also ensure that there is no intraspecific or interspecific brood mixing through farming-out, as has been frequently observed in P. microlepis (Yanagisawa, 1985; Ochi \& Yanagisawa, 1996), which might have caused complications in the estimates of the genetic basis of laterality. These fish, however, are notoriously difficult to keep and breed in the laboratory and only very few cases of laboratory spawnings have been reported so far. This will continue to make future laboratory and genetic studies on the behavioural and developmental aspects of this interesting morphological and ecological dimorphism difficult. 
Lateral dimorphism in mouth-opening direction is not limited to scale-eating Lake Tanganyika cichlids such as $P$. microlepis. Other fishes such as herbivorous cichlids Telmatochromis temporalis Boulenger (Mboko et al., 1998) and Neolamprologus moorii (Boulenger) (Hori et al., 2007) and a freshwater omnivorous goby Rhinogobius flumineus (Mizuno) (Seki et al., 2000) also show this characteristic. Similar to scale-eaters, the laterality of these fishes is also strongly associated with mouth usage in foraging behaviour (i.e. lateralized foraging behaviour). In the herbivorous cichlid T. temporalis, the right morph tends to use the right side of the jaw more frequently and the left morph the left side (Mboko et al., 1998). Although evidence for ecological effects of laterality is convincing, an understanding of the mechanisms of laterality itself is lacking. Thus, the exact developmental bases of laterality and the mechanisms by which the dimorphism is maintained ecologically would be interesting to explore in these fishes across different habitats.

We thank E. Hespeler, L. Luncz and A. Renz for laboratory assistance, K. Elmer for assistance with genotyping microsatellites, C. Baker for editing Fig. 3 and K. Elmer, H. Gunter, F. Henning and S. Wielgoss for discussions. Sampling in Zambia was done with a permit issued by the Department of Fisheries, Republic of Zambia, to A.M. This research was financially supported by the Deutsche Forschungsgemeinschaft and the University of Konstanz to A.M.

\section{References}

Bruford, M. W., Hanotte, O., Brookfield, J. F. Y. \& Burke, T. (1998). Multi-locus and singlelocus DNA fingerprinting. In Molecular Genetic Analysis of Populations (Hoelzel, A. R., ed.), pp. 283-336. New York, NY: Oxford University Press.

Clement, M., Posada, D. \& Crandall, K. A. (2000). TCS: a computer program to estimate gene genealogies. Molecular Ecology 9, 1657-1659. doi: 10.1046/j.1365-294x.2000. $01020 . x$

Crandall, K. A. \& Templeton, A. R. (1993). Empirical tests of some predictions from coalescent theory with applications to intra-specific phylogeny reconstruction. Genetics 134, 959-969.

Davison, A., Chiba, S., Barton, N. H. \& Clarke, B. (2005). Speciation and gene flow between snails of opposite chirality. Public Library of Science Biology 3, 1559-1571.

Excoffier, L., Smouse, P. E. \& Quattro, J. M. (1992). Analysis of molecular variance inferred from metric distances among DNA haplotypes: application to human mitochondrial DNA restriction data. Genetics 131, 497-491.

Excoffier, L., Laval, G. \& Schneider, S. (2005). Arlequin (version 3.0): an integrated software package for population genetics data analysis. Evolutionary Bioinformatics Online 1, $47-50$.

Fitzpatrick, B. M., Fordyce, J. A. \& Gavrilets, S. (2008). What, if anything, is sympatric speciation? Journal of Evolutionary Biology 21, 1452-1459. doi: 10.1111/j.1420-9101. 2008.01611.x

Freeman, G. \& Lundelius, J. W. (1982). The developmental genetics of dextrality and sinistrality in the gastropod Lymnaea peregra. Roux's Archives of Developmental Biology $191,69-83$.

Hashimoto, H., Mizuta, A., Okada, N., Suzuki, T., Tagawa, M., Tabata, K., Yokoyama, Y., Sakaguchi, M., Tanaka, M. \& Toyohara, H. (2002). Isolation and characterization of a Japanese flounder clonal line, reversed, which exhibits reversal of metamorphic left-right asymmetry. Mechanisms of Development 111, 17-24. doi: 10.1016/S09254773(01)00596-2

Hori, M. (1993). Frequency-dependent natural selection in the handedness of scale-eating cichlid fish. Science 260, 216-219. doi: 10.1126/science.260.5105.216 
Hori, M., Ochi, H. \& Kohda, M. (2007). Inheritance pattern of lateral dimorphism in two cichlids (a scale eater, Perissodus microlepsis, and an herbivore, Neolamprologus moorii) in Lake Tanganyika. Zoological Science 24, 486-492. doi: 10.2108/zsj.24.486

Jesson, L. K. \& Barrett, S. C. H. (2002). The genetics of mirror-image flowers. Proceedings of the Royal Society B 269, 1835-1839.

Johnson, M. S. (1976). Allozymes and area effects in Cepaea nemoralis on the western Berkshire Downs. Heredity 36, 105-121.

Johnson, M. S. (1982). Polymorphism for direction of coil in Partula suturalis: behavioural isolation and positive frequency-dependent selection. Heredity 49, 145-151.

Koblmüller, S., Duftner, N., Sefc, K. M., Aigner, U., Rogetzer, M. \& Sturmbauer, C. (2009). Phylogeographic structure and gene flow in the scalc-eating cichlid Perissodus microlepis (Teleostei, Perciformes, Cichlidae) in southern Lake Tananyika. Zoologica Scripta 38, 257-268. doi: 10.1111/j.1463-6409.2008.00378.x

Lee, W., Conroy, J., Howell, W. H. \& Kocher, T. D. (1995). Structure and evolution of teleost mitochondrial control regions. Journal of Molecular Evolution 41, 54-66. doi: 10.1007/BF00174041

Mboko, S. K., Kohda, M. \& Hori, M. (1998). Asymmetry of mouth-opening of a small herbivorous cichlid fish Telmatochromis temporalis in Lake Tanganyika. Zoological Science 15, 405-408.

Meyer, A., Morrissey, J. M. \& Schartl, M. (1994). Recurrent origin of a sexually selected trait in Xiphophorus fishes inferred from a molecular phylogeny. Nature 368, 539-542. doi: 10.1038/368539a0

Nshombo, M., Yanagisawa, Y. \& Nagoshi, M. (1985). Scale-eating in Perissodus microlepis (Cichlidae) and change of its food habit with growth. Japanese Journal of Ichthyology 32, 66-73.

Ochi, H. \& Yanagisawa, Y. (1996). Interspecific brood-mixing in Tanganyikan cichlids. Environmental Biology of Fishes 45, 141-149.

Palmer, A. R. (1996). From symmetry to asymmetry: phylogenetic patterns of asymmetry variation in animals and their evolutionary significance. Proceedings of the National Academy of Sciences of the United States of America 93, 14279-14286. doi: 10.1073/ pnas.93.25.14279

Palmer, A. R. (2004). Symmetry breaking and the evolution of development. Science 306, $828-833$.

Palmer, A. R. (2009). Animal asymmetry. Current Biology 19, R473-R477.

Palmer, A. R. (2010). Scale-eating cichlids: from hand(ed) to mouth. Journal of Biology 9 , 11.

Petit, R. J., Mousadik, A. E. \& Pons, O. (1998). Identifying populations for conservation on the basis of genetic markers. Conservation Biology 12, 844-855. doi: 10.1111/j.15231739.1998.96489.x

Raymond, M. \& Rousset, F. (1995). GENEPOP (version 1.2): population genetics software for exact tests and ecumenicism. Journal of Heredity 86, 248-249.

Rousset, F. (2008). GENEPOP'007: a complete re-implementation of the GENEPOP software for Windows and Linux. Molecular Ecology Resources 8, 103-106. doi: 10.1111/ j.1471-8286.2007.01931.x

Sanetra, M., Henning, F., Fukamachi, S. \& Meyer, A. (2009). A microsatellite-based genetic linkage map of the cichlid fish, Astatotilapia burtoni (Teleostei): a comparison of genomic architectures among rapidly speciating cichlids. Genetics 182, 387-397. doi: 10.1534/genetics. 108.089367

Schilthuizen, M., Scott, B. J., Cabanban, A. S. \& Craze, P. G. (2005). Population structure and coil dimorphism in a tropical land snail. Heredity 95, 216-220. doi: 10.1037/sj.hdy. 6800715

Schilthuizen, M., Craze, P. G., Cabanban, A. S., Davison, A., Stone, J., Gittenberger, E. \& Scott, B. J. (2007). Sexual selection maintains whole-body chiral dimorphism in snails. Journal of Evolutionary Biology 20, 1941-1949. doi: 10.1111/j.1420-9101.2007. 01370.x

Seki, S., Kohda, M. \& Hori, M. (2000). Asymmetry of mouth morph of a freshwater goby, Rhinogobius flumineus. Zoological Science 17, 1321-1325. 
Stewart, T. A. \& Albertson, R. C. (2010). Evolution of a unique predatory feeding apparatus: functional anatomy, development and genetic locus for jaw laterality in Lake Tanganyika scale-eating cichlids. BMC Biology 8, 8, doi:10.1186/1741-7007-8-8.

Takahashi, R., Watanabe, K., Nishida, M. \& Hori, M. (2007). Evolution of feeding specialization in Tanganyikan scale-eating cichlids: a molecular phylogenetic approach. $B M C$ Evolutionary Biology 7, 195. doi: 10.1186/1471-2148-7-195

Takahashi, T. \& Hori, M. (2008). Evidence of disassortative mating in a Tanganyikan cichlid fish and its role in the maintenance of intrapopulation dimorphism. Biology Letters 4, 497-499. doi: 10.1098/rsbl.2008.0244

Templeton, A. R. (2006). Population Genetics and Microevolutionary Theory. Hoboken, NJ: John Wiley \& Sons, Inc.

Templeton, A. R. \& Sing, C. F. (1993). A cladistic analysis of phenotypic associations with haplotypes inferred from restriction endonuclease mapping. IV. Nested analyses with cladogram uncertainty and recombination. Genetics 134, 659-669.

Templeton, A. R., Crandall, K. A. \& Sing, C. F. (1992). A cladistic analysis of phenotypic associations with haplotypes inferred from restriction endonuclease mapping and DNA sequence data. III. Cladogram estimation. Genetics 132, 619-633.

Van Dooren, T. J., van Goor, H. A. \& van Putten, M. (2010). Handedness and asymmetry in scale-eating cichlids: antisymmetries of different strength. Evolution, doi:10.1111/j. 1558-5646.2010.00977.

Weir, B. S. \& Cockerham, C. C. (1984). Estimating $F$-statistics for the analysis of population structure. Evolution 38, 1358-1370. doi: 10.2307/2408641

Yamaguchi, T. (1977). Studies on the handedness of the fiddler crab, Uca lacteal. Biological Bulletin 152, 424-436.

Yanagisawa, Y. (1985). Parental strategy of the cichlid fish Perissodus microlepis, with particular reference to intraspecific brood 'farming out'. Environmental Biology of Fishes $12,241-249$.

\section{Electronic Reference}

Goudet, J. (2001). FSTAT: a program to estimate and test gene diversities and fixation indices, version 2.9.3. Available at http://www.unil.ch/izea/softwares/fstat.html 
APpendix. Summary of genetic diversity in left and right samples of Perissodus microlepis at 13 microsatellite loci. Sample sizes ( $N$ ), observed number of alleles per locus $\left(N_{\mathrm{a}}\right), P$ values of exact tests for deviation from Hardy-Weinberg equilibrium $\left(\mathrm{H}-\mathrm{W}\right.$ test), expected $\left(H_{\mathrm{E}}\right)$ and observed heterozygosity $\left(H_{\mathrm{O}}\right)$ and allelic richness $(\mathrm{AR})$ within a given sample per locus are provided. $P$ value in boldface denotes significant deviation from $\mathrm{H}-\mathrm{W}$ test after a Bonferroni correction for multiple testing. KV, Kalambo Village; TL, Toby Veall's Lodge

\begin{tabular}{|c|c|c|c|c|c|c|c|c|c|c|c|c|c|c|c|}
\hline Sample & Locus & Abur25 & Abur28 & Abur 44 & Abur6l & Abur90 & Abur98 & Abur 110 & Abur111 & Aburl 17 & Abur162 & Abur 163 & Abur 165 & Abur 178 & Mean \\
\hline \multirow[t]{6}{*}{ KV-left } & $N$ & 20 & 22 & 22 & 20 & 20 & 21 & 23 & 22 & 19 & 23 & 15 & 22 & 21 & 20.8 \\
\hline & $N_{\mathrm{a}}$ & 5 & 2 & 8 & 9 & 6 & 8 & 4 & 4 & 8 & 3 & 5 & 4 & 4 & 5.4 \\
\hline & $\mathrm{H}$-W tests $(P)$ & 0.820 & 1.000 & 0.984 & 0.493 & 0.596 & 0.423 & 0.441 & 0.868 & 0.687 & 0.023 & 0.388 & 0.668 & 0.159 & 一 \\
\hline & $H_{\mathrm{E}}$ & 0.717 & 0.359 & 0.655 & 0.823 & 0.663 & 0.664 & 0.437 & 0.576 & 0.761 & 0.465 & 0.738 & 0.569 & 0.765 & 0.630 \\
\hline & $H_{\mathrm{O}}$ & 0.700 & 0.364 & 0.773 & 0.900 & 0.600 & 0.667 & 0.478 & 0.546 & 0.842 & $0 \cdot 304$ & 0.600 & 0.546 & 0.857 & 0.629 \\
\hline & $\mathrm{AR}$ & 4.930 & 2.000 & $7 \cdot 136$ & 7.988 & 5.440 & 6.913 & 3.872 & 3.680 & $7 \cdot 354$ & 2.963 & $5 \cdot 000$ & $3 \cdot 682$ & 4.000 & 4.997 \\
\hline \multirow[t]{6}{*}{ KV-right } & $N$ & 26 & 25 & 25 & 26 & 25 & 22 & 26 & 25 & 24 & 26 & 20 & 26 & 25 & 24.7 \\
\hline & $N_{\mathrm{a}}$ & 5 & 2 & 10 & 8 & 5 & 6 & 4 & 6 & 9 & 4 & 5 & 4 & 4 & $5 \cdot 5$ \\
\hline & $\mathrm{H}-\mathrm{W}$ tests $(P)$ & 0.294 & 0.372 & 0.878 & 0.812 & $0 \cdot 135$ & 0.524 & $0 \cdot 244$ & 0.262 & 0.642 & 0.074 & 0.396 & 0.187 & 0.188 & - \\
\hline & $H_{\mathrm{E}}$ & 0.612 & 0.429 & 0.763 & 0.807 & 0.620 & 0.584 & 0.610 & 0.708 & 0.805 & 0.280 & 0.744 & 0.610 & 0.758 & 0.641 \\
\hline & $H_{\mathrm{O}}$ & 0.500 & 0.520 & 0.800 & 0.808 & 0.600 & 0.500 & 0.615 & 0.640 & 0.875 & 0.231 & 0.650 & 0.500 & 0.680 & 0.609 \\
\hline & AR & 4.506 & 2.000 & $8 \cdot 179$ & 7.051 & 4.521 & $5 \cdot 018$ & 3.972 & $5 \cdot 521$ & 7.957 & 3.480 & 4.750 & $3 \cdot 577$ & 4.000 & 4.964 \\
\hline \multirow[t]{6}{*}{ TL-left } & $N$ & 25 & 29 & 29 & 27 & 27 & 27 & 30 & 29 & 26 & 29 & 19 & 30 & 26 & $27 \cdot 2$ \\
\hline & $N_{\mathrm{a}}$ & 8 & 2 & 9 & 9 & 5 & 9 & 6 & 5 & 13 & 4 & 5 & 4 & 4 & $6 \cdot 4$ \\
\hline & $\mathrm{H}-\mathrm{W}$ tests $(P)$ & 0.877 & 1.000 & 0.121 & 0.903 & 0.843 & 0.184 & 0.553 & 0.942 & 0.329 & 0.527 & 0.568 & 0.293 & 0.206 & - \\
\hline & $H_{\mathrm{E}}$ & 0.767 & 0.160 & 0.717 & 0.818 & 0.514 & 0.703 & 0.550 & 0.649 & 0.886 & 0.424 & 0.700 & 0.605 & 0.750 & 0.634 \\
\hline & $H_{\mathrm{O}}$ & 0.680 & 0.172 & 0.655 & 0.778 & 0.593 & 0.704 & 0.567 & 0.621 & 0.846 & 0.448 & 0.579 & 0.700 & 0.692 & 0.618 \\
\hline & $\mathrm{AR}$ & $6 \cdot 720$ & 1.979 & 7.731 & 7.643 & 4.098 & 7.369 & 4.936 & 4.033 & 10.788 & 3.034 & 4.579 & 3.972 & 4.000 & 5.453 \\
\hline \multirow[t]{6}{*}{ TL-right } & $N$ & 27 & 29 & 29 & 27 & 28 & 29 & 30 & 27 & 26 & 26 & 23 & 30 & 27 & $27 \cdot 5$ \\
\hline & $N_{\mathrm{a}}$ & 7 & 2 & 12 & 11 & 4 & 9 & 5 & 5 & 11 & 5 & 7 & 4 & 4 & $6 \cdot 6$ \\
\hline & H-W tests $(P)$ & 0.708 & 1.000 & 0.309 & 0.008 & 1.000 & 0.196 & 0.035 & 0.681 & 0.003 & 1.000 & 0.056 & 0.741 & 0.768 & 一 \\
\hline & $H_{\mathrm{E}}$ & 0.735 & 0.373 & 0.725 & 0.813 & 0.629 & 0.666 & 0.616 & 0.590 & 0.860 & 0.249 & 0.756 & 0.626 & 0.718 & 0.643 \\
\hline & $H_{\mathrm{O}}$ & $0 \cdot 815$ & 0.414 & 0.690 & 0.630 & 0.643 & 0.621 & $0 \cdot 500$ & 0.556 & 0.731 & 0.269 & 0.565 & 0.633 & 0.815 & 0.606 \\
\hline & AR & 5.916 & 2.000 & 8.865 & 8.496 & 3.536 & $7 \cdot 147$ & 4.725 & $4 \cdot 111$ & 9.441 & 3.704 & 6.187 & 3.995 & 3.995 & 5.548 \\
\hline
\end{tabular}

